\title{
Categorization and Hierarchy of Workplace Bullying Strategies: A Delphi Survey
}

\author{
Álvaro Rodríguez-Carballeira, Jordi Escartín Solanelles, Bienvenido \\ Visauta Vinacua, Clara Porrúa García, and Javier Martín-Peña \\ Universidad de Barcelona (Spain)
}

\begin{abstract}
This paper reports a study of the characteristics of psychological abuse strategies deployed in the workplace (mobbing or workplace bullying). Based on a literature review, the aim of the present study is two fold: firstly to propose a new taxonomy of mobbing strategies and to provide an operational definition for each of them, and secondly, to assess this taxonomy with the aid of several experts, by using a Delphi survey, and to evaluate the severity of each of the mobbing strategies. The experts were asked to evaluate the adequacy and the severity of the definitions for each mobbing strategy. Thirty experts working in various professions (psychology, medicine, law, sociology, etc.) participated in a two-round Delphi survey. The experts estimated that the new taxonomy and the operational definitions were appropriate, establishing content and construct validity. They ranked the workplace bullying strategies in terms of descending importance: strategies of direct nature, followed by indirect strategies. Theoretical implications of the study, its limitations and future research are discussed.
\end{abstract}

Keywords: workplace bullying, mobbing, workplace violence, Delphi survey, severity, weighted scores.

\begin{abstract}
Este estudio psicosocial analiza las estrategias de abuso psicológico que se aplican en el lugar de trabajo (mobbing o bullying laboral). A partir de una revisión de la literatura científica, el primer objetivo pretende proponer una nueva clasificación de las estrategias del mobbing y dotar de una definición operativa a cada una de dichas estrategias. El segundo objetivo trata de evaluar esta clasificación y la severidad de las estrategias de mobbing a través del juicio de un panel de expertos utilizando para ello un estudio Delphi. Los expertos tuvieron que juzgar la adecuación de las estrategias y sus definiciones, y evaluar cuantitativamente la severidad de cada estrategia en el conjunto del mobbing. Treinta expertos de diferentes profesiones (psicólogos, médicos, abogados, sociólogos, etc.) participaron en el estudio Delphi de dos pasaciones. Los expertos juzgaron la nueva categorización y sus definiciones operativas como apropiadas estableciendo de este modo, validez de contenido y de constructo. Además, jerarquizaron las estrategias de mobbing resultando en su conjunto con mayor severidad las de naturaleza más directa, por encima de aquéllas más indirectas. Finalmente, se discuten los resultados y las limitaciones de esta investigación, así como las implicaciones teóricas y prácticas que pueden derivarse de ella.

Palabras clave: bullying laboral, mobbing, violencia laboral, método Delphi, severidad, puntajes ponderados.
\end{abstract}

The study was financially supported by Ministry of Education and Science, and the FEDER funds (SE J2007-61957).

Correspondence concerning this article should be addressed to Álvaro Rodríguez-Carballeira. Departamento de Psicología Social. Universidad de Barcelona. Pg. Vall d'Hebron, 171. 08035 Barcelona. (Spain). Phone: +34-933125178. Fax: +34-934021366. E-mail: alvaro.rodriguez@ub.edu 
Mobbing or workplace bullying - as a form of non-physical interpersonal aggression (Birkeland \& Einarsen, 2007) - has generated considerable social and academic interest over the last two decades. Research has systematically shown that workplace bullying, is not simply an interpersonal issue, but is an organizational dynamic that impacts all who are exposed, such as witnessing coworkers and firms as a whole (Hoel, Einarsen \& Cooper, 2003; Mayhew \& Chappell, 2007; Salin, 2003). Einarsen and Mikkelsen (2003, p. 127) classified mobbing as a "more crippling and devastating problem for employees than all other work-related stress put together".

Many studies have sought to define mobbing (e.g., Leymann, 1996) and reveal its various forms and prevalence (e.g., Zapf, Einarsen, Hoel \& Vartia, 2003; Zapf, Escartín, Einarsen, Hoel \& Vartia, 2010). Einarsen, Hoel, Zapf and Cooper (2003, p. 15) proposed one of the most accepted definitions of this phenomenon to date: "Bullying at work means harassing, offending, socially excluding someone or negatively affecting someone's work tasks. In order for the label bullying (or mobbing) to be applied to a particular activity, interaction or process it has to occur repeatedly and regularly (e.g. weekly) and over a period of time (e.g. about six months)". These authors also defined mobbing as "an escalating process in the course of which the person confronted ends up in an inferior position and becomes the target of systematic negative social acts". Finally, they tried to differentiate bullying from other phenomena such as conflicts: "A conflict cannot be called bullying if the incident is an isolated event or if two parties of approximately equal "strength" are in conflict". We will use the terms "bullying" and "mobbing" interchangeably throughout the article.

Most definitions of mobbing and its components, used by researchers (i.e., Moayed, Daraiseh, Shell \& Salem, 2006), include four essential criteria, (a) the frequency, (b) the duration, (c) the power imbalance and (d) the negative effect on the target. However, as it is noticed by Hoel and Beale (2006, p. 241) "although the growing convergence of definitions of workplace bullying in recent years, there is not unanimous support for the defining characteristics"; there is a clear emphasis on the targets' perspective, to the detriment of establishing a set of independent of the target criteria that would rely on verification or validation of act by third parties. As Keashly (2001) points out, the subtle nature of certain behaviors makes it difficult to accurately describe them, undermining the target's own abilities to discern what exactly has occurred. Therefore, although someone could argue that in order to have a psychological effect on the individual, a potentially harassing behavior has to be perceived and evaluated (Frese \& Zapf, 1988; Lazarus \& Folkeman, 1986), as it has been noticed by Magley, Hulin, Fitzgerald and Denardo (1999, p. 399) "it is the fact of the harassment and not its label or appraisal as stressful that leads to outcomes". Likewise, Agervold
(2007) stressed that it is essential to identify certain types of behaviors as bullying, and to allow this definition to be independent of the target perspective. Keashly (1998, p. 103) argued that "research directed at identifying types of behaviors as well as the variability in judgments associated with these behaviors would be an important step. This research is not only important for the theoretical development of the construct but also has implications for workplace policies and prevention/intervention work". This is important according to Lengnick-Hall (1995), because an objective conceptualization is necessary in connection with legal issues and cases of internal disciplinary hearings. Although the creation of a legal response to workplace bullying does not seem to be an easy task (Yamada, 2000), different policy goals such as (a) prevention, (b) self-help, (c) relief, compensation and restoration and (d) punishment, should offer a starting point for identifying the main priorities. In this sense, McCarthy (2003, p. 235) noticed that "commonly accepted meanings of bullying have tended to accentuate an assemblage of individual, medical and therapeutic, managerial and particular legal remedies. Concerns have been raised about consequences arising from the manner in which bullying is conceptualized".

Building on this, it can be argued that for research on workplace bullying to succeed, the field requires some understanding of what precisely is "workplace bullying". If the field of organizational psychology is truly aiming at having a deeper understanding of this phenomenon, it raises several questions of whether mobbing is a homogeneous construct, or whether there are typical types or categories of bullying, which can be differentiated. In other words: Which are the core components of mobbing? Which of these components are more severe? Which could be more punishable from a legal perspective? Although this paper will not try to answer all these questions, they have certainly oriented the present study.

Following the statements of several authors like Saunders, Huynh and Goodman-Delahunty, (2007 p. 352) who argue that "the possible underreporting of workplace bullying as a result of differing definitions as to what workplace bullying entails can have serious consequences for organisations where the bullying occurs"; and Smith, Cowie, Olafsson and Liefoogh (2002, p. 1131) who stated that "this imperfect correspondence between popular and scientific definition of terms such as bullying is an issue that researcher must remain aware of'; it is important both theoretically and practically, to clarify the definition of bullying.

In this sense, Einarsen (2000, p. 398) stressed that "treating bullying as a pure subjective phenomenon meaning different things to different people may make it difficult to develop practical interventions for controlling or eradicating the problem. And this must be addressed and taken into account, both in research and in organizations conflict management strategies". 


\section{Categorization of workplace bullying strategies}

Various taxonomies of the components of psychological abuse in the workplace have been proposed (i.e., Fendrich, Woodword \& Richman, 2002; Rayner \& Hoel, 1997). The use of factor analysis has yielded between two and seven factors (e.g., Leymann, 1990; Zapf, Knorf \& Kulla; 1996). Zapf (1999) categorized five main types of bullying behaviors: (a) work-related bullying, (b) social isolation, (c) personal attacks, (d) verbal threats and (e) spreading rumours.

In addition to this, other studies have conceptualised mobbing using Buss's (1961) tipology of aggression: verbal-physical; direct-indirect; and active-passive. For example, Baron and Neumann (1996) differentiated between direct and indirect aggressive behaviors. More specifically, they used the following definitions: "Direct forms of aggression are ones in which harm is delivered directly to the victim, while indirect forms involve the delivery of harm through the actions of other agents or through assaults on persons or objects valued by the victim" (p. 164). They found that direct forms of aggression, were rated as significantly more frequent than indirect forms of aggression.

Taking these studies together, it seems that there are some categories which are considered as typical of workplace bullying. Specifically, what these categories have in common is their identification of strategies of abuse, that emphasise the emotional aspects of mobbing, including insults, rumours, gossip and threats (e.g., Moreno, Rodríguez, Martínez \& Gálvez, 2007; Richman et al, 1999). Furthermore, another feature that these taxonomies have in common, is the emphasis they give to contextual aspects such as isolation and exclusion, not only in their physical meaning, but especially in their social dimension. Finally, the work related aspects of the phenomenon have been stressed, such as devaluation of the work or being given tasks with impossible deadlines (Einarsen \& Mikkelsen, 2003).

However after reviewing these categories, some components seem to have received only little attention. For example, few studies appear to have considered aspects such as control and manipulation of information or control and abuse of working conditions (i.e., Aquino, 2000; Einarsen \& Raknes, 1997; Leymann, 1990; Rayner, 1999). In this sense, the analysis of the various existing taxonomies points out several differences between them, making it difficult to talk about a consensus in the delimitation of mobbing and its components. For this reason, some theoretical and practical benefits could be derived not only from a new taxonomy encompassing the previous ones, but also from the content and construct validity added by a group of experts through a Delphi survey.

\section{Hierarchy of workplace bullying strategies}

From a more general perspective, research in health psychology has focused mainly on checklists or interview schedules regarding life events, which require the respondents to review all demanding situations in the past and to supply subjective ratings of incidence and severity (i.e., Holmes \& Rahe, 1967; Sarason, Johnson \& Siegel, 1978). As noted by Turner and Wheaton (1995) these ratings of cumulative life stress, can lead to an ambiguous sum score, which may obscure various exposure conditions and can cover important information. These authors suggest that in order to yield an index of severity, one can ask independent judges to rate the event along a number of dimensions. This provides useful information that should be supplemented by data regarding the victims' cognitive appraisals.

Focusing on previous research looking at workplace bullying, it can be found that while considerable attention has been placed on its detection, assessment of its severity has not been equally studied (Escartín, Rodríguez-Carballeira, Zapf, Porrúa \& Martín-Peña, 2009). However, the severity of mobbing behaviors is very important specially when planning treatment interventions. Different studies argue that workplace bullying could be characterized by the degree of harm it is responsible for (Davenport, Schwartz \& Elliot, 2002). Likewise, LutgenSandvik, Tracy and Alberts (2007) introduced the concept of bullying degree as the sum of the number of different negative acts (referred as "intensity"), and their duration and frequency. This concept was defined as "a cumulative score reflecting the intensity, frequency and duration of negative acts that constitute workplace bullying” (p. 844), which implies that as the degree of bullying increases, so do the negative outcomes. Hoel, Faragher and Cooper (2004) argued that bullying behaviors are not necessarily equally damaging. Yet, no one has ever explored whether individual behaviors may be particularly severe, using other methodologies than self-report questionnaires (Agervold, 2007; Lengnick-Hall, 1995), independently of the negative psychological and physical health outcomes of target persons (i.e., Escartín, Arrieta \& RodríguezCarballeira, 2009; Escartín, Rodríguez-Carballeira, Porrúa $\&$ Martin-Pena, 2008). That is, many instruments merely sum items without regard to differences in the impact of behaviors.

Conceptually, some of the workplace bullying behaviors may not be exactly comparable in terms of severity (Keashly, 1998). For instance, behaviors such as "removing work tools" are probably not equivalent in severity to other kind of behaviors such as "addressing with disrespect and rejection through insults". This means that without severity weights, a change in the overall frequency of bullying behaviors, may not accurately reflect the change in the overall level of victimization. 
In sum the present study focuses on an approach that is worthwhile considering, both in theory and practice, because it can offer further support to the results obtained by previous research on self-reports (i.e., Davenport et al., 2002; Lutgen-Sandvik, 2007) through expert opinions.

\section{The Delphi Survey}

Taking into account what has been said above, this study tries to apply a technique that have been used in related fields such as school bullying (Cross, Pintabona, Hamilton \& Hall, 2000; Cross, Pintabona, Hall, Hamilton \& Erceg, 2004) and elder abuse (Daly \& Jogerst, 2005; Hudson, 1991), but has not yet been applied to investigate mobbing strategies at work.

The Delphi method was used to obtain a reliable unanimous agreement from a group of mobbing experts. The method is characterised by different features, such as (a) anonymity for all respondents, (b) iteration with controlled feedback and (c) statistically interpretable group response (for more details, see Delbecq \& Gustafson, 1984 and Lindstone \& Turoff, 1975). In other words, this technique has proved useful in situations in which the individual opinions can be combined in order to examine an area in which understanding is incomplete or for which no general consensus has been achieved, which is the case of workplace bullying (Einarsen et al., 2003; Saunders et al., 2007). Therefore, this survey can help to establish content and construct validity for the definitions of workplace bullying categories (Turoff \& Hiltz, 1996). Furthermore, given that the participants do not engage in direct interaction, it is easier to avoid any biases derived from the identities of the experts and the pressures that this might entail (Lindstone \& Turoff, 1975).

\section{Research aims}

In line with Zapf et al., (2003, p. 122) who pointed out that "studies are needed to further substantiate the concept of bullying in the workplace" the first objective of the present study was to propose a new taxonomy of mobbing strategies (by categories and subcategories) accompanied by their respective operational definitions. As a second objective, this study seeks to assess this taxonomy with the aid of several experts, by using a Delphi survey, and to evaluate the severity of each of the mobbing strategies.

\section{Method}

\section{Sample}

In order to conduct the Delphi survey a panel of professional experts in the field of mobbing were enrolled. Professional and university websites, as well as publications and conferences, were used to approach the experts. Experts were from Spain and were selected on the basis of two criteria: (a) their professional experience in the study of mobbing and in providing support for victims; and, (b) their research experience in the field. The group of experts was made up primarily of professionals and researchers in the fields of psychology, law, medicine and sociology. Participants were unaware of other participants' identities. The final sample comprised 30 subjects, all of whom participated voluntarily. Their anonymity was guaranteed at all times.

\section{Materials}

In order to conduct the Delphi survey, a taxonomy of psychological abuse strategies in the workplace (see Table 1) was used. The formulation of this taxonomy constituted the primary objective of this study.

To devise this taxonomy the definition provided by Einarsen et al. (2003) was used, also previous studies of mobbing or workplace bullying, in all their forms of expression and denomination were utilized, as well as scales and instruments for measuring this form of harassment (in particular, the Leymann Inventory of Psychological Terrorization -Leymann, 1990- and the Negative Acts Questionnaire -Einarsen \& Raknes, 1997- were gathered and analysed). To this end, different databases were used, such as PsycInfo or Medline, to name a few.

The information extracted from this material was analysed and systematically classified. Four independent researchers, with previous experience in the study of different types of psychological abuse, extracted the mobbing strategies, and grouped them within separate categories and subcategories. The inter-rater agreement based on the researchers individually showed high reliability between scores (Kappa value: .826 for symmetric measures, $p<.01)$. Then, the researchers reach an agreement on a taxonomy of the psychological abuse strategies.

\section{Procedure}

In drawing up this new taxonomy of mobbing strategies, an exhaustive search, selection, recompilation and analysis of studies of psychological abuse in the main databases, and cited in the previous section, was undertaken. From this set of theoretical and empirical studies, we extracted the various taxonomies regarding the components of psychological abuse, including the factors or items in the measurement scales that were examined. Using this material a new taxonomy was developed, and enabled us to devise an all-inclusive taxonomy of abuse strategies, which incorporates all behaviors from the most obvious to the most subtle. 
Then, to evaluate whether this taxonomy was adequate and complete, and to determine the severity of each of the psychological abuse strategies, a survey of experts, by adopting the classic Delphi method, was conducted (Delbecq \& Van de Ven, 1984; Lindstone \& Turoff, 1975). In this way, we sought to achieve a consensus among the specialists, regarding the components of mobbing and the severity attached to each of them.

Having made contact with the experts, we briefed them explaining the purpose of the survey. After having received their acceptance to participate in the study, the first questionnaire was sent out, followed by the second questionnaire. Both questionnaires were sent by email and were accompanied by their respective set of instructions.

\section{Questionnaire Development}

\section{Round one}

In the first round, respondents were given definitions for each of the six categories and subcategories described above, and asked if the particular categories were considered as relevant to the phenomenon of workplace bullying. Moreover, they were asked to assess the severity of each component of the taxonomy. In order to achieve this, the experts were asked to distribute 100 points between categories and another 100 points between each group of subcategories. This procedure was chosen to facilitate the experts' decision making and to assure the scores' variability.

Furthermore, the experts were able to suggest changes if they considered that the categories proposed by the researchers were inadequate. In other words, respondents were asked if there were any additional categories they would expect to encounter. No additional categories were suggested in any of the 6 categories. Experts believed that the categories proposed by the researchers, were very detailed and covered the most important aspects of workplace bullying. Very few suggestions were made by the participants (in the qualitative comments) in both rounds: 1 and 2 (see next section). When analysed, the majority of the "new" issues raised, were identified as being already part of the categories described.

\section{Round two}

Having received the first set of questionnaires with their scores and before sending them out again, the mean values of the different scores allocated by the participants, their standard deviation, and the highest and lowest scores in each category were analysed. In this sense, the second questionnaire was set up so the experts could evaluate and allocate scores once more to the categories and subcategories, following the results from the statistics described above. Moreover, participants were given the option of changing their first score or leaving it unchanged, according to the criteria of each expert.

\section{Results}

\section{Categorization of workplace bullying strategies}

The first objective of the study was to develop a new taxonomy of psychological abuse strategies used in the workplace with their respective operational definitions, establishing content and construct validity. Thus, a new taxonomy, containing six principal categories of mobbing with various subcategories is presented (see Table 1), as well as a working definition of each of them. In the case of both the denomination of categories and the specification of the operational definitions, an approach centred on the actions of the bully was adopted, avoiding any reference to the consequences that these have or may have on the target.

The taxonomy includes distinct components of abuse that can, in some cases, occur together. The first three categories refer to the abuse strategies, related principally to indirect aggressive behaviors and the work environment of the victim: number 1 refers to the social activities and the physical work space; number 2 refers to the information given and received while carrying out the work tasks; and number 3 refers to the working conditions. Contrastingly, the last three categories, focused more closely on direct aggressive behaviors and the experiences of the individuals affected. More specifically, they refer to abuse strategies, which emphasise, respectively, elements of an emotional (4), cognitive (5) and behavioral (6) nature.

\section{Hierarchy of workplace bullying strategies}

The second objective of this study was to analyse the severity of each of the categories of mobbing. To achive this, the mean scores of the second and definitive assessment carried out by the panel of experts was taken as reference. Then the average values for each category and subcategory used for classifying the components of mobbing was obtained (see Figure 1). In the diagram, the subcategories are shown as being hierarchical in relation to the value obtained by the category to which they belong, so that the sum of each group of subcategories is equal to the total value of the parent category. A similar procedure has been followed in other Delphi surveys (i.e., Reetoo, Harrington \& Macdonald, 2005).

The categories of psychological abuse that presented the highest degree of severity, were those that emphasise the more direct aspects of the phenomenon ("emotional abuse", $\bar{X}=19.26$; "professional discredit and denigration", $\bar{X}=18.13$ ). Contrastingly, the categories 
Table 1

Taxonomy of psychological abuse in the workplace (mobbing)

Type Nature
1. ISOLATION: Restricting the worker's interaction with his or her co-workers and/or physically
separating him or her from them, seeking his or her marginalization or exclusion.
1.1. Physical isolation: Physically separating the worker from his or her co-workers as a
means of isolating him or her.
1.2. Social isolation: Hindering or impeding communication and interaction between the
worker and his or her co-workers, and restricting his or her participation in communal
activities.
2. CONTROL AND MANIPULATION OF INFORMATION: Selecting and manipulating the
information received by the worker, lying to him or her, and stemming or interfering
with the information that the worker transmits.
3. CONTROL-ABUSE OF WORKING CONDITIONS: Intervening or acting negligently in the
work environment and working conditions in order to upset the worker as he or she
attempts to perform his or her tasks, or to put his or her health at risk.
3.1. Obstructionism: Removing or damaging the possessions or work tools of the worker and
limiting his or her access to other useful elements, interfering with them or hiding them.
3.2. Dangerous work: Assigning to the worker tasks that are prejudicial to, or
put at risk, his or her health.

4. EMOTIONAL ABUSE: Offensive actions and expressions aimed especially at attacking, injuring and sneering at the worker's feelings and emotions.

4.1. Intimidation and threats: Intimidating the worker by warning him or her of the physical and psychological harm, or other injuries, that will befall them or their environment if

Emotion they do not act as they are told to or as they are expected to.

4.2 Disrespect, humiliation and rejection of the person: Attacking the worker, addressing him or her with disrespect and rejection through insults, slanderous comments, taunts, mockery, false accusations, rumors and other disparaging remarks.

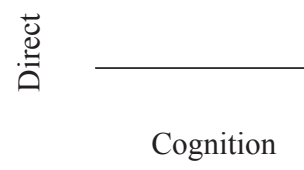

5. PROFESSIONAL DISCREDIT AND DENIGRATION: Discrediting and denigrating the worker's professional reputation and standing, belittling his or her knowledge, experience, efforts, performance, etc.

6. DEVALUATION OF THE ROLE IN THE WORKPLACE: Undervaluing the importance of the

Behavior role of the worker, unjustifiably relieving the worker of his or her responsibilities or assigning the worker tasks that are useless, impossible or clearly inferior to his category in the organization.

whose greatest emphasis lies in the indirect aspects were those that received the lowest severity scores ("isolation", $\bar{X}=15.77$; and the "control-abuse of working conditions", $\bar{X}=11.80$ ). Significant differences were found between the hierarchy proposed by the panel of experts regarding direct and indirect aggressive behaviors in workplace bullying $(Z=-3.617 ; p<.001)$.

However, when the six categories were compared, no significant differences were found, with the exception of the third category ("Control-abuse of working conditions") which differed from all the rest (e.g., "Emotional abuse" $Z=-.971$; $p<.001$; "Isolation" $Z=2.403 ; p=.016$ ), and the first category
("Isolation") and the fourth category ("Emotional abuse") which were different from each other $(Z=2.328 ; p=.020)$.

Furthermore, in order to compare the scores allocated by the panel of experts in the two surveys, the Wilcoxon z-test was used, given that the paired data were not normally distributed. The results showed that there were no significant differences between the scores allocated during the first and the second survey. The categories with the smallest differences in both surveys were "professional discredit and denigration" $(p=.95)$, and the "devaluation of the role in the workplace" $(p=.81)$. The categories that showed the greatest differences between the two 


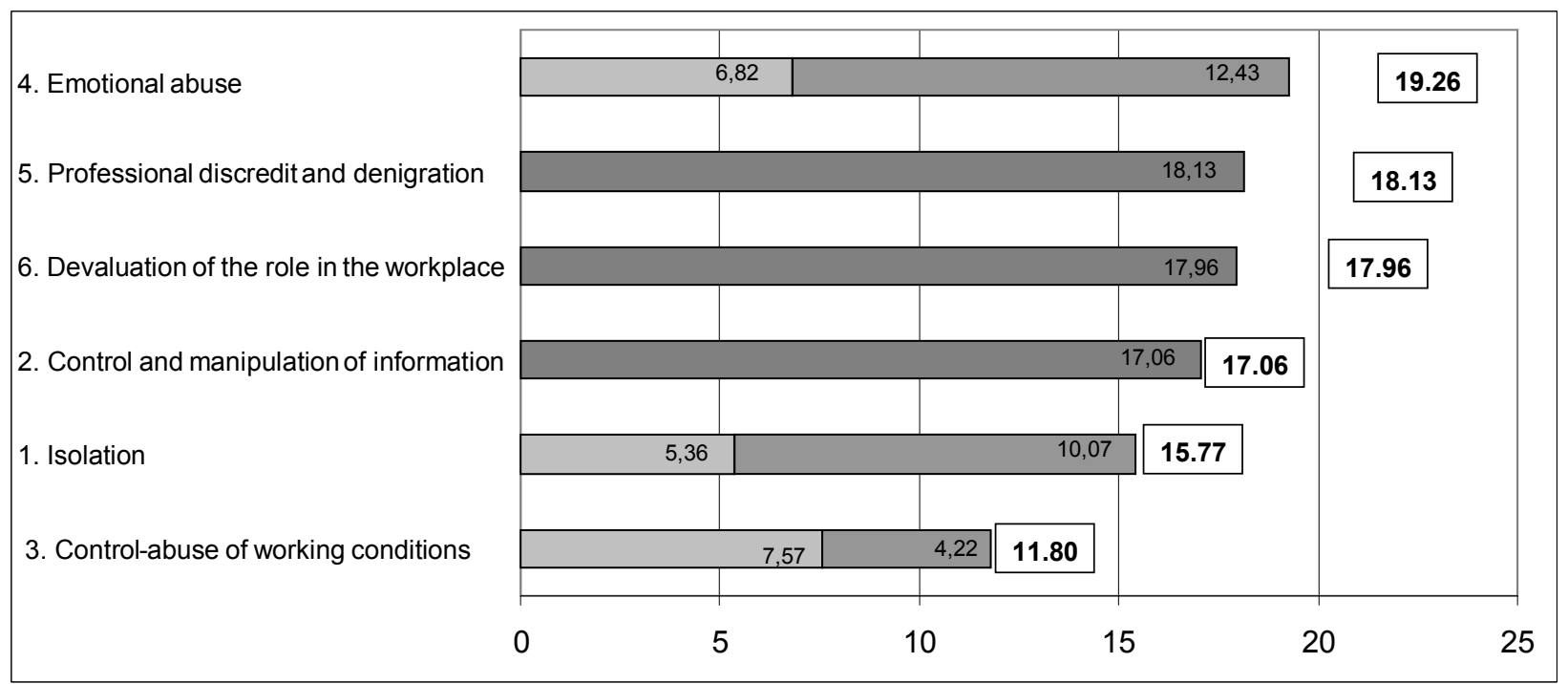

Note. The mean values of each category and subcategory are shown in descending order.

${ }^{\text {a }}$ Number of each subcategory

${ }^{\mathrm{b}}$ Mean of each subcategory

Figure 1. Severity of the various components of mobbing.

surveys were "control-abuse of working conditions" $(p=.50)$, and "emotional abuse" $(p=.63)$.

Finally, descriptive statistics for each of the categories and subcategories, as evaluated by the group of experts, were obtained. Likewise, in order to verify the goodness of fit of the results, the correlations between the two scores given in the first and second rounds were calculated, and finally, any possible differences between the mean values of the two surveys were analysed (see Table 2).

The results also showed that the Spearman correlations between the scores allocated by the group of experts were significant at $p<.01$ (two-sided) for both the categories and the subcategories, indicating a high degree of correlation between them. Thus, the most notable interdependence was found in the category "control and manipulation of information" $(p=.90)$; while in the subcategories, the most notable interdependence was recorded by "physical isolation" $(p=.98)$.

\section{Discussion}

The first aim of the present study was to develop a new taxonomy of mobbing strategies, using categories and subcategories, accompanied by their respective operational definitions. As a second objective the study sought to assess this taxonomy and to determine the degree of severity of each mobbing strategy, by conducting a Delphi survey with experts.

Results indicated how the experts validated a taxonomy and the operational definitions of six components of workplace bullying. Furthermore, the experts scored with different weights these components depending on their severity. Emotional abuse was judged as the most severe strategy, professional discredit and denigration as the second one, and devaluation of the role in the workplace as the third one. Finally, control and manipulation of information, isolation, and control and abuse of working conditions, were judged as the least severe according to the experts.

The results of this study are in accordance with previous empirical and theoretical research (Martín-Peña, Rodríguez-Carballeira, Escartín, Porrúa, \& Winkel, 2010). The dimensions found in the present study are similar to those found in several studies (i.e., Coyne, Seigne \& Randall, 2000; Jennifer, Cowie \& Ananiadou, 2003; Zapf, 1999). According to the distinction between work-related and personal-related bullying strategies (Moreno et al., 2007), "emotional abuse" is comparable with personal-related bullying and the rest of categories are partially equivalent to work-related bullying. Furthermore, these findings differ partially from existing taxonomies of workplace bullying strategies. Such previous taxonomies overestimate or under represent some strategies like "control and manipulation of information" or "abuse of working conditions" (i.e., Aquino, 2000; Quine, 2003; Rayner, 1999). Moayed et al. (2006) pointed out that when listing previous taxonomies of workplace bullying strategies: "there may be an obvious overlap between these categories" (p. 322).

The results also showed a taxonomy of the severity of mobbing behaviors according to the experts' scores. A 
RODRÍGUEZ-CARBALLEIRA, ESCARTÍN, VISAUTA, PORRÚA, AND MARTÍN-PEÑA,

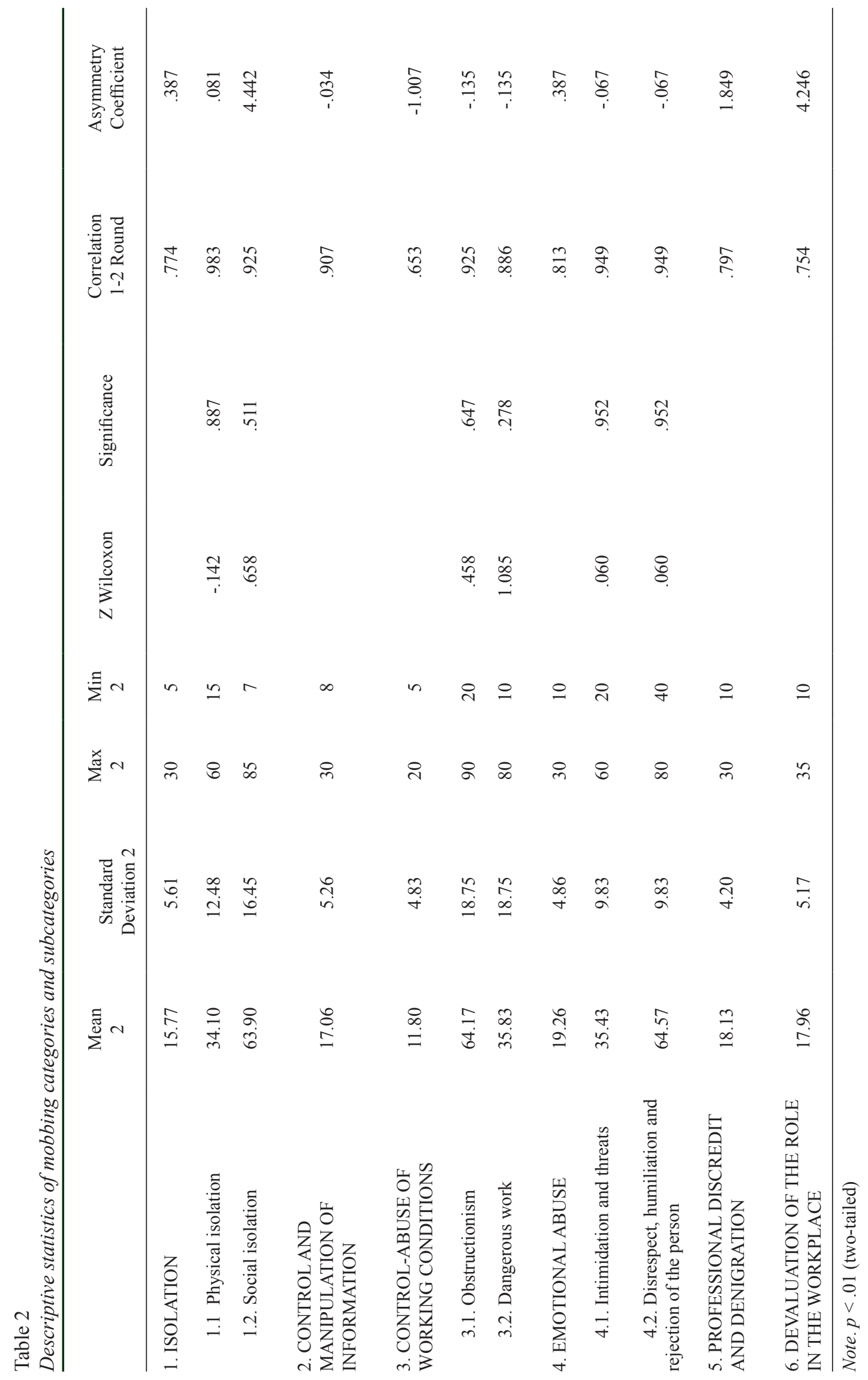


marked predominance of the abuse strategies, which can be considered as most direct, was found, as opposed to those that were considered as indirect. In line with other studies (i.e., Hansen, et al., 2006), attacks against the person, were scored higher than those aggressions aimed at influencing the working environment. Thus, the mobbing strategy with the highest severity score, was the emotional abuse, and particularly when it was related to "disrespect, humiliation or rejection of the person", this is perhaps the strategy that attacks more directly the identity of the individual. These results are also in line with previous research (i.e., Keashly, 2001; Keashly, \& Harvey, 2005; Lutgen-Sandvik, 2003; Mikkelsen \& Einarsen, 2002) that use the term "emotional abuse" when referring to mobbing, with the argument that emotional aggressions represent its principal component. For example, Einarsen (1999) reported that humiliation and offence lie at the heart of mobbing. Likewise, Niedl (1996) reported that the most significant components of bullying are repeated hostile acts of humiliation and intimidation directed to the victim.

Overall, this finding supports the assumption that workplace bullying behaviors vary in their severity, and adds value to both the academic and the applied fields, in the sense that results obtained by previous research on self-reports (i.e., Davenport et al., 2002; Lutgen-Sandvik, 2007) are validated by expert opinions.

From a practical viewpoint, all these findings should contribute to the development of intervention strategies, in which a clear statement of the tolerated and non-tolerated behaviors could become important and beneficial in showing that an employer is serious about preventing prohibited conduct (i.e., Gutek, 1997; Hill \& Phillips, 1997), as organizational behavior research has demonstrated (i.e., Stockdale, Bisom-Rapp, O'Connoer \& Gutek, 2004). In other words, using the taxonomy obtained in this study, training efforts may be more effective in establishing a workplace climate of intolerance for harassment and bullying, placing emphasis on different aspects such as the development of mediation skills, as well as stress and conflict management (i.e., Glomb \& Liao, 2003; Zapf \& Gross, 2001). All these actions can facilitate the planning and organisation of these intervention programs and lead to more specific forms of training (i.e., Saunders et al., 2007).

Furthermore, results from the present study should contribute to a greater precision and delimitation of mobbing in the workplace, which can have practical implications in the legal domain, as noted by McCarthy (2003, p. 236): "Bullying gives sharper definition to forms of violence that mostly fall outside present legal definitions of assault, sexual harassment, discrimination, health and safety, equal opportunities and human rights". Coherently, Mayhew and Chappell (2007) noted that taxonomy is important for identifying the most appropriate risk control measures. Thus, the taxonomy proposed here may contribute to a more accurate assessment of abusive behaviors in the workplace and their legal consequences (Escartín, Rodríguez-Carballeira, Gómez-Benito \& Zapf, in press; Escartín, Zapf, Arrieta \& Rodríguez-Carballeira, in press). In this sense, Yamada (2004) stressed that the law plays an important role in setting minimum boundaries of appropriate behavior, encouraging preventive measures, providing compensation, and serving as a means of dispute resolution.

Some of the study limitations should be stated, for example, although the importance of the broader variables that characterise each organisation is recognised by the researchers, such variables have fallen outside the scope of this study. Indeed, other studies have highlighted numerous organizational variables and processes related to mobbing (i.e., Meseguer, Soler, García-Izquierdo, Sáez \& Sánchez, 2007). Furthermore, because the selection of the experts was not random, limitations on how much information the present sample can provide should be pointed out. However, it is important to note that because workplace bullying represents a burgeoning area in organizational psychology, it made it more difficult to use probability sampling. As a consequence, the selection of the sample was based on assumptions regarding the population of interest. Finally, the present study has presented a taxonomy of workplace bullying strategies according to their severity; nevertheless, when developing a scale using this taxonomy, one must be aware of previous research within health psychology (i.e., Turner \& Wheaton, 1995), which has found that assigning different degrees of severity to different events, not always results in higher correlations with health outcomes.

\section{References}

Agervold, M. (2007). Bullying at work: A discussion of definitions and prevalence, based on an empirical study. Scandinavian Journal of Psychology, 48, 161-172.

Aquino, K. (2000). Structural and individual determinants of workplace victimization: the effects of hierarchical status and conflict management style. Journal of Management, 26, 171-193.

Baron, R.,\& Neumann, J. (1996). Workplace violence and workplace aggression: Evidence on their relative frequency and potential causes. Aggressive Behaviour, 22, 161-173.

Birkeland, M., \& Einarsen, S. (2007). Sampling in research on interpersonal aggression. Aggressive Behaviour, 33, 1-8.

Buss, A. (1961). The Psychology of Aggression. New York: Wiley.

Coyne, I., Seigne, E., \& Randall, P. (2000). Predicting workplace victim status from personality. European Journal of Work and Organizational Psychology, 9, 335-349.

Cross, D., Pintabona, Y., Hamilton, G., \& Hall, M. (2000). A Delphi study of successful practice in the prevention, reduction and management of bullying in schools. Bentley, Western Australia: Curtin University of Technology, Western Australian Centre for Health Promotion Research. 
Cross, D., Pintabona., Y., Hall, M., Hamilton, G., \& Erceg, E. (2004). Validated guidelines for school-based bullying prevention and management. International Journal of Mental Health Promotion, 6(3), 34-42.

Daly, J. \& Jogerst, G. (2005). Definitions and indicators of elder abuse: A Delphi survey of APS caseworkers. Journal of Elder Abuse \& Neglect, 17(1), 1-19.

Davenport, N., Schwartz, R., \& Elliot, G. (2002). Mobbing. Emotional abuse in the American workplace. USA: Civil Society Publishing.

Delbecq, A., \& Van de Ven, G. (1984). Técnicas grupales para la planeación. México: Ed. Trillas.

Einarsen, S. (1999). The nature and causes of bullying at work. International Journal of Manpower, 20(1/2), 16-27.

Einarsen, S. (2000). Harassment and bullying at work: A review of the Scandinavian approach. Aggression and Violent Behaviour: A Review Journal, 4, 371-401.

Einarsen, S., Hoel, H., Zapf, D., \& Cooper, C. (Eds). (2003). The Concept of Bullying at work. The European Tradition.

In Bullying and Emotional Abuse in the Workplace: International Perspectives in Research and Practice. (pp. 3-30). London/New York: Taylor \& Francis.

Einarsen, S., \& Mikkelsen, E. (2003). Individual effects of exposure to bullying at work. In S. Einarsen, H. Hoel, D. Zapf, \& C. Cooper (Eds), Bullying and Emotional Abuse in the Workplace: International Perspectives in Research and Practice. (pp. 127-144). London/New York: Taylor \& Francis.

Einarsen, S., \& Raknes, I. (1997). Harassment at work and the victimization of men. Violence and Victims, 12, 247-263.

Escartín, J., Arrieta, C., \& Rodríguez-Carballeira, A. (2009). Mobbing o Acoso laboral: Revisión de los principales aspectos teórico-metodológicos que dificultan su estudio. Actualidades en Psicología, 23(110), 1-19.

Escartín, J.; Rodríguez-Carballeira, A.; Gómez-Benito, J., Zapf, D. (in press). Development and validation of the workplace bullying scale (EAPA-T). International Journal of Clinical and Health Psychology.

Escartín, J., Rodríguez-Carballeira, A., Porrúa, C., \& MartínPeña, J. (2008). Estudio y análisis sobre cómo perciben el mobbing los trabajadores. Revista de Psicología Social, 23(2), 203-211.

Escartín, J., Rodríguez-Carballeira, A., Zapf, D., Porrúa, C., \& Martín-Peña, J. (2009). Perceived severity of various bullying behaviours at work and the relevance of exposure to bullying. Work and Stress, 23(3), 191-205.

Escartín, J., Zapf, D., Arrieta, C., \& Rodríguez-Carballeira, A. (in press). Workers' perception of workplace bullying: A crosscultural study. European Journal of Work and Organizational Psychology.

Fendrich, M., Woodward, P., \& Richman, J. (2002). The structure of harassment and abuse in the workplace: a factorial comparison of two measures. Violence and Victims, 17(4), 491-505.
Frese, M., \& Zapf, D. (1988). Methodological issues in the study of work stress: Objective vs subjective measurement of work stress and the question of longitudinal studies. In C. Cooper and R. Payne (Eds), Causes, coping, and consequences of stress at work. (pp. 375-411). New York: John Wiley \& Sons Ltd.

Glomb, T., \& Liao, H. (2003). Interpersonal aggression in work groups: Social influence, reciprocal, and individual effects. Academy of Management Journal, 46, 486-496.

Gutek, B. (1997). Sexual harassment policy initiatives. In: W. O'Donohue, (Ed.), Sexual harassment: Theory, research and treatment. Boston: Allyn \& Bacon, (pp. 185-198).

Hansen, A., Hogh, A., Persson, R., Karlson, B., Garde, A., \& Orbaek, P. (2006). Bullying at work, health outcomes, and physiological stress response. Journal of Psychosomatic Research, 60(1), 63-72.

Hill, D., \& Phillips, J. (1997). Preventing sexual harassment. In J. Phillips (Ed.), In action: Measuring return on investment, 2. (pp. 17-35). Alexandria: American Society for Training and Development.

Hoel, H., \& Beale, D. (2006). Workplace bullying, psychological perspectives and industrial relations: towards a contextualised and interdisciplinary approach. British Journal of Industrial Relations, 44(2), 239-262.

Hoel, H., Einarsen, S., \& Cooper, C. (2003). Organizational effects of bullying. In S. Einarsen, H. Hoel, D. Zapf \& C. Cooper (Eds), Bullying and Emotional Abuse in the Workplace: International Perspectives in Research and Practice (pp. 145-161). London/New York: Taylor \& Francis.

Hoel, H., Faragher, B., \& Cooper, C. (2004). Bullying is detrimental to health, but all bullying behaviours are not necessarily equally damaging. British Journal of Guidance and Counselling, 32(3), 367-387.

Holmes, T., \& Rahe, R. (1967). The Social Readjustment Rating Scale. Journal of Psychosomatic Research, 2, 216.

Hudson, M. (1991). Elder mistreatment: A taxonomy with definitions by Delphi. Journal of Elder Abuse \& Neglect, $3(2), 1-20$.

Jennifer, D., Cowie, H., \& Ananiadou, K. (2003). Perceptions and experience of workplace bullying in five different populations. Aggressive Behaviour, 29, 489-496.

Keashly, L. (1998). Emotional abuse in the workplace: conceptual and empirical issues. Journal of Emotional Abuse, 1(1), 85117.

Keashly, L. (2001). Interpersonal and systemic aspects of emotional abuse at work: The target's perspective. Violence \& Victims, 16(3), 233-268.

Keashly, L., \& Harvey, S. (2005). Emotional abuse at work. In P. Spector, \& S. Fox (Eds), Counterproductive workplace behaviour; an integration of both actor and recipient perspectives on causes and consequences (pp. 201-236). Washington, DC: American Psychological Association.

Lazarus, R., \& Folkeman, S. (1986) Cognitive theories of stress and the issue of circularity. In M. L. Appley, \& R. Trumbull (Eds.), Dynamics of stress. New York: Plenum Press. 
Lengnick-Hall, M. (1995). Sexual harassment research: A methodological critique. Personnel Psychology 48, 841-864.

Leymann, H. (1990). Mobbing and psychological terror at workplaces. Violence and Victims, 5, 119-126.

Leymann, H. (1996). The content and development of mobbing at work. European Journal of Work and Organizational Psychology, 5(2), 165-184.

Lindstone H, \& Turoff, M. (1995). The Delphi method: techniques and applications. Reading: Addison-Wesley.

Lutgen-Sandvik, P. (2003). The communicative cycle of employee emotional abuse. Management Communication Quarterly, 16(4), 471-501.

Lutgen-Sandvik, P. (2007). Bad words will never hurt me: Abuse and bullying at work, a comparison between two worker samples. Ohio Communication Journal, 45, 27-52.

Lutgen-Sandvik, P., Tracy, S., \& Alberts, J. (2007). Burned by bullying in the American workplace: Prevalence, perception, degree and impact. Journal of Management Studies, 44(6), 837-862.

Magley, V., Hulin, C., Fitzgerald, L.; \& Denardo, M. (1999). Outcomes of self-labeling sexual harassment. Journal of Applied Psychology, 84, 390-402.

Martín-Peña, J., Rodríguez-Carballeira, Á., Escartín, J., Porrúa, C. \& Winkel, F. W. (2010). Strategies of psychological terrorism perpetrated by ETA's network: Delimitation and classification. Psicothema, 22(1), 118-123.

Mayhew, C., \& Chappell, D. (2007). Workplace Violence: An overview of patterns of risk and the emotional/stress consequences on targets. International Journal of Law and Psychiatry, 30, 327-339.

McCarthy, P. (2003). Bullying at work: a postmodern experience. In S. Einarsen, H. Hoel, D. Zapf, \& C. Cooper (Eds), Bullying and Emotional Abuse in the Workplace. International Perspectives in Research and Practice. (pp. 231-245). London \& New York: Taylor \& Francis.

Meseguer, M., Soler, M., García-Izquierdo, M., Sáez, M., \& Sánchez, J. (2007). Los factores psicosociales de riesgo en el trabajo como predictores del mobbing. Psicothema, 19(2), 225-230.

Mikkelsen, E., \& Einarsen, S. (2002). Relationships between exposure to bullying at work and psychological and psychosomatic health complaints. Scandinavian Journal of Psychology, 43, 397-405.

Moayed, F., Daraiseh, N., Shell, R., \& Salem, S. (2006). Workplace bullying: a systematic review of risk factors and outcomes. Theoretical Issues in Ergonomics Science, 7(3), 311-327.

Moreno, B., Rodríguez, A., Martínez, M., \& Gálvez, M. (2007). Assessing workplace bullying: Spanish validation of a reduced version of the Negative Acts Questionnaire. The Spanish Journal of Psychology, 10(2), 449-457.

Niedl, K. (1996). Mobbing and Well-being: Economic and Personnel Development Implications. European Journal of Work and Organizational Psychology, 5(2), 239-250.
Quine, L. (2003). Workplace bullying, psychological distress, and job satisfaction in junior doctors. Cambridge Quarterly of Health Ethics, 12, 91-101.

Rayner, C. (1999). From Research to implementation: finding leverage for prevention. International Journal of Manpower, 20(1/2), 28-38.

Rayner, C., \& Hoel, H. (1997). A summary review of literature relating to workplace bullying. Applied Social Psychology, 7(3), 181-191.

Reetoo, K., Harrington, J., \& Macdonald, E. (2005). Required competencies of occupational physicians - a Delphi survey of UK customers. Occupational Environmental Medicine, 62, 406-413.

Richman, J., Rospenda, K., Nawyn, S., Flaherty, J., Fendrich, M., \& Drum, M. (1999). Sexual harassment and generalized workplace abuse among university employees: Prevalence and mental health correlates. American Journal of Public Health, 89, 358-364.

Salin, D. (2003). Ways of explaining workplace bullying: a review of enabling, motivating and precipitating structures and processes in the work environment. Human Relations, 56(10), 1213-1232.

Sarason, I. G., Johnson, J. H., \& Siegel, J. M. (1978). Assessing the impact of life changes: Development of the life experiences survey. Journal of Consulting and Clinical Psychology, 46, 932-946.

Saunders, P., Huynh, A., \& Goodman-Delahunty, J. (2007). Defining workplace bullying behaviour professional lay definitions of workplace bullying. Law and Psychiatry, 30, 340-354.

Smith, P., Cowie, H., Olafsson, R., \& Liefooghe, A. (2002). Definitions of bullying; a comparison of terms used, and age and gender differences, in a fourteen-country international comparison. Child development, 73(4), 1119-1133.

Stockdale, M., Bisom-Rapp, S., O’Connor, M., \& Gutek, B. (2004). Coming to terms with zero-tolerance sexual harassment policies. Journal of Forensic Psychology Practice, 4, 65-78.

Turner, R., \& Wheaton, B. (1995). Checklist measurement of stressful life events. In S. Cohen, R. C. Kessler, \& L. U. Gordon (Eds.), Measuring stress: A guide for health and social scientists. (pp. 29-58). New York: Oxford University Press.

Turoff, M., \& Hiltz, S. (1996). Computer Based Delphi Processes. In M. Adler \& E. Ziglio (Eds.), Gazing into the Oracle: The Delphi Method and Its Application to Social Policy and Public Health, London: Jessica Kingsley Publishers.

Yamada, D. (2000). The phenomenon of "Worplace Bullying" and the need for Status-Blind Hostile Work Environment Protection. The Georgetown Law Journal, 88(3), 474-536.

Yamada, D. (2004). Crafting a legislative response to workplace bullying. Employee Rights and Employment Policy Journal, 8, 474-521.

Zapf, D. (1999). Organizational, work group related and personal causes of mobbing/bullying at work. International Journal of Manpower, 20(1/2), 70-85. 
Zapf, D., Einarsen, S., Hoel, H., \& Vartia, M. (2003). Empirical findings on bullying in the workplace. In S. Einarsen, H. Hoel, D. Zapf, \& C. Cooper (Eds.), Bullying and Emotional Abuse in the Workplace. International Perspectives in Research and Practice. (pp. 103-126). London \& New York: Taylor \& Francis.

Zapf, D., Escartín, J., Einarsen, S., Hoel, H., \& Vartia, M. (2010). Empirical findings on the prevalence rate and risk groups of bullying in the workplace. In S. Einarsen, H. Hoel, D. Zapf, \& C. L. Cooper (Eds.), Workplace bullying: Development in theory, research and practice. London \& New York: Taylor \& Francis.
Zapf, D., \& Gross, C. (2001). Conflict escalation and coping with workplace bullying: A replication and extension. European Journal of Work and Organizational Psychology, 10(4), 497-522.

Zapf, D., Knorf, C., \& Kulla, M. (1996). On the relationships between mobbing factors, and job content, social work environment, and health outcomes. European Journal of Work and Organizational Psychology, 5(2), 215-237.

Received October 8, 2008 Revision received March 2, 2009 Accepted June 16, 2009 